University of Wollongong

Research Online

Faculty of Law, Humanities and the Arts Papers (Archive)

Faculty of Arts, Social Sciences \& Humanities

$1-1-2012$

Social connectedness and generalized trust: a longitudinal perspective

Patrick Sturgis

University of Southampton

Roger Patulny

University of Wollongong, rpatulny@uow.edu.au

Nick Allum

University of Essex

Franz Buscha

University of Westminster

Follow this and additional works at: https://ro.uow.edu.au/lhapapers

Part of the Arts and Humanities Commons, and the Law Commons

Research Online is the open access institutional repository for the University of Wollongong. For further information contact the UOW Library: research-pubs@uow.edu.au 


\title{
Social connectedness and generalized trust: a longitudinal perspective
}

\begin{abstract}
Social, or 'generalized', trust refers to beliefs that people hold about how other people in society will in general act towards them. Can people in general be trusted? Or must one be careful in dealing with people? Research on the antecedents of social trust has typically relied on cross-sectional regression estimators to evaluate putative causes. Our contention is that much of this research over-estimates the importance of many of these causes because of the failure to account for unmeasured confounding influences. In this paper we use longitudinal data to assess the causal status of a particularly prominent mooted cause of trust: the degree to which individuals are socially integrated via formal membership of civic organisations and through friendship networks. We fit a range of regression estimators to repeated measures data from the UK for the period 1998 to 2008. Our results show little support for the widely held view that social trust results from integration within social networks, of either a formal or an informal nature.
\end{abstract}

\section{Keywords}

generalized, longitudinal, connectedness, social, trust, perspective

Disciplines

Arts and Humanities | Law

\section{Publication Details}

Sturgis, P., Patulny, R., Allum, N. and Buscha, F. (2012). Social connectedness and generalized trust: a longitudinal perspective. ISER Working Paper Series, 2012-19 1-23. 


\section{Social Connectedness and Generalized Trust: A Longitudinal Perspective}

Patrick Sturgis

University of Southampton

Roger Patulny

University of Wollongong

Nick Allum

University of Essex

Franz Buscha

University of Westminster

No. 2012-19

27 September 2012
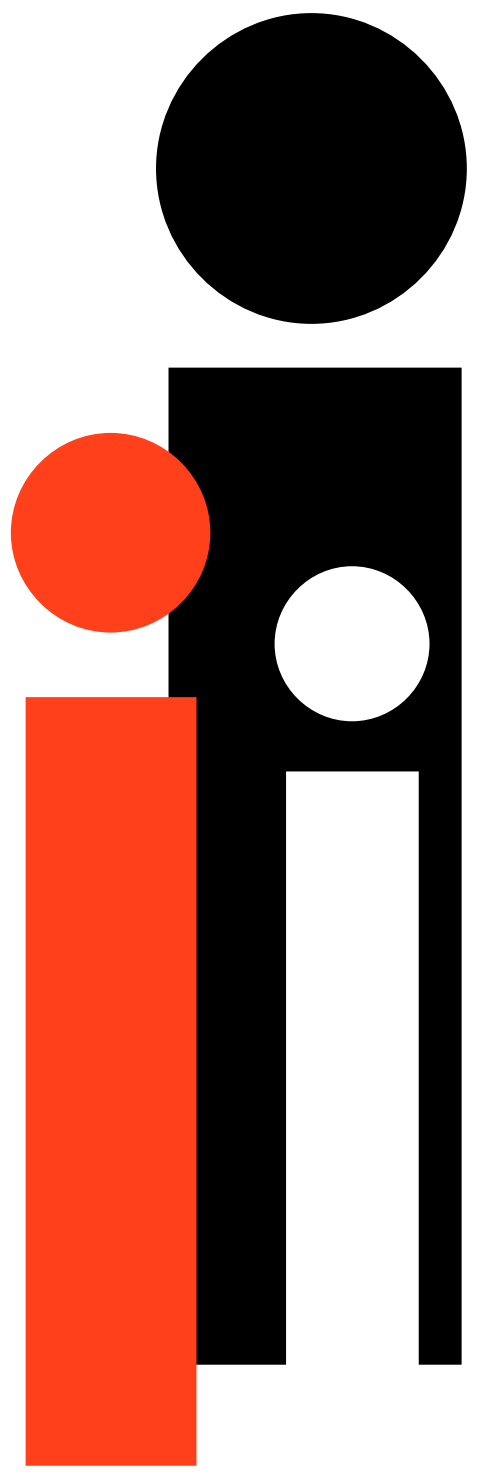

INSTITUTE FOR SOCIAL \& ECONOMIC RESEARCH 


\section{NON-TECHNICAL SUMMARY}

Social, or 'generalized', trust refers to beliefs that people hold about how other people in society will in general act towards them. Can people in general be trusted? Or must one be careful in dealing with people? This type of 'thin', or 'horizontal' trust is different from the kind that people invest in family, friends, colleagues, acquaintances, and institutions that are known to them. Social trust is more like a core value or belief; an abstract evaluation of the moral standards of the society in which we live. This kind of trust is usually regarded as a good thing, because it makes it easier for people to co-operate without the need for strict contracts, regulation and enforcement. As Stolle puts it, trust is "a key social resource that seems to oil the wheels of the market economy and democratic politics" (Stolle 2003 p19).

Because trust is so often seen as a good thing, it is important to understand why some people trust more than others and therefore understand how it might be possible to increase social trust in the population. A great deal of research has been focussed on this topic but our contention in this paper is that much of it is hampered by severe methodological limitations. In particular, the predominant reliance on cross-sectional survey data means that we cannot be sure that the things that appear to be related to trust are the real causes of differences in trust between individuals. In this paper we try to overcome some of these limitations by using longitudinal data that captures changes in people's levels of trust over time. We can then examine how some of the putative causes of trust relate to these changes. In so doing, we can rule out many of the potential confounding influences that have not been measured in previous studies and thereby enable us to make a more robust evaluation of what might really be important.

In particular, we assess the influence of a particularly prominent mooted cause of trust: the degree to which individuals are socially integrated via formal membership of civic organisations and voluntary groups but also through informal social networks that exist between friends and neighbours. We do this by fitting a range of statistical models to repeated measures data from the UK for the period 1998 to 2008. Our results show little support for the widely held view that social trust results from integration within social networks, of either a formal or an informal nature. 


\title{
Social Connectedness and Generalized Trust: A Longitudinal Perspective
}

\author{
Patrick Sturgis, University of Southampton* \\ Roger Patulny, University of Wollongong \\ Nick Allum, University of Essex \\ Franz Buscha, University of Westminster
}

\begin{abstract}
*Address correspondence to Patrick Sturgis, Division of Social Statistics, University of Southampton, Southampton, SO17 1BJ, or p.sturgis@ soton.ac.uk.

This research was conducted as part of the Social and Political Trust (SaPT) project (www.uptap.net/project21.html) funded by a grant from the UK Economic and Social Research Council (ESRC award No. 163-25-0021).
\end{abstract}

\begin{abstract}
Social, or 'generalized', trust refers to beliefs that people hold about how other people in society will in general act towards them. Can people in general be trusted? Or must one be careful in dealing with people? Research on the antecedents of social trust has typically relied on cross-sectional regression estimators to evaluate putative causes. Our contention is that much of this research over-estimates the importance of many of these causes because of the failure to account for unmeasured confounding influences. In this paper we use longitudinal data to assess the causal status of a particularly prominent mooted cause of trust: the degree to which individuals are socially integrated via formal membership of civic organisations and through friendship networks. We fit a range of regression estimators to repeated measures data from the UK for the period 1998 to 2008. Our results show little support for the widely held view that social trust results from integration within social networks, of either a formal or an informal nature.
\end{abstract}

KEYWORDS: SOCIAL TRUST; PANEL DATA; FIXED EFFECTS; SOCIAL CAPITAL. 


\section{INTRODUCTION}

Social, or 'generalized' trust relates to beliefs held by individuals in a given society about the moral orientation and incentive structure of a diffuse, unknown 'other' (Delhey and Newton 2005). This type of 'thin', or 'horizontal' trust must be differentiated from the instrumental, 'strategic' trust we invest in family, friends, colleagues, acquaintances, and institutions that are known to us (Hardin 1999; Putnam 2000; Uslaner 2002). While strategic trust is developed over time through direct personal experience, social trust is more akin to a core value or belief; an abstract evaluation of the moral standards of the society in which we live (Delhey and Newton 2003). To the extent that individuals within a society are inclined to make positive evaluations of the trustworthiness of their fellow citizens, various normatively benign consequences may be expected to follow at both the individual and societal levels. This is because social trust is postulated to facilitate co-operative behaviour in the absence of information about the trustworthiness of the 'other'. This type of diffuse trust, it is argued, reduces social and economic transaction costs by lowering the need for contracts, legal and regulatory frameworks, and other forms of coercive authority (Hardin 1999; Luhmann 1979) ${ }^{1}$. It has been posited as the key mechanism through which dis-connected individuals with divergent preferences can overcome collective action problems (Arrow 1974; Fukayama 1995; Parsons). As Stolle puts it, trust is "a key social resource that seems to oil the wheels of the market economy and democratic politics" (Stolle 2003 p19).

If trust is key to the attainment of social and economic prosperity, it goes without saying that we should devote serious attention to understanding how it might be nurtured, developed, and maintained. The case for deepening our understanding of the origins of trust is all the more compelling in the context of its apparent precipitate decline in advanced western democracies during the latter part of the twentieth century (Hall 1999; Putnam 2000; Robinson and Jackson 2001). Our contention in this paper is that much of the existing body of research into the causes of social trust is hampered by limitations of methodology and data. In particular, the predominant

\footnotetext{
${ }^{1}$ Though see Cook, Hardin and Levi (2005) for the multifarious ways in which cooperation can exist in the absence of trust.
} 
reliance on cross-sectional regression estimators is likely to result in substantial overestimation of the true effect of putative causes.

Our contribution is both methodological and substantive. Methodologically, we show that conclusions based on cross-sectional regression can be fundamentally altered once appropriate defence against unobserved confounding variables is introduced. Substantively, we assess the causal status of a particularly prominent mooted cause of trust in the theoretical literature - the degree to which individuals are socially integrated via formal membership of civic organisations and voluntary groups but also through informal social networks that exist between friends and neighbours. We do this by fitting a range of regression estimators to repeated measures data from the UK for the period 1998 to 2008. Our results show little support for the widely held view that social trust results from integration within social networks, of either a formal or an informal nature. We begin with a review of the relevant literature, before describing our data, key measures and analytical strategy. We then present our results and conclude with a discussion of their implications for our understanding of the relationship between both formal and informal social connections and generalised trust.

\section{SOCIAL CONNECTIONS AND TRUST}

Discussions about interpersonal trust and its correlates very often take place in the context of the wider notion of social capital. An enormous quantity of theoretical and empirical work on social capital has appeared in recent decades, and the concept has found its way into the lexicons of government and policymakers, as well as of sociologists, economists, political scientists and those working in other academic disciplines. Although definitions of social capital are varied, the essential idea behind the concept is that social networks are useful. For individuals, this means that social investments have expected positive returns (Lin 2001). Although one can view the accumulation of social capital as a rational goal (Coleman 1988a), it may be acquired simply as a by-product of making affective ties with people in a non-instrumental manner (Crow 2004). We can distinguish between two types of network that can yield such returns: informal and formal. The former are identified in the literature as predominantly friendship or extended familial networks (Granovetter 1973). The latter are composed of participation in formally constituted civic organisations 
(Putnam 2000). Membership of either type of network could be advantageous in a host of different ways, for example enhanced job opportunities, greater resilience to economic and social hardship, better mental health and wellbeing.

Where does trust enter into this conceptual network? The idea that generalised trust emerges from the formal networks of civil society has a long and venerable history (Almond and Verba 1963; de Tocqueville 1835; Mill 1937; Simmel 1903). The essence of the idea is that those who join various types of civic association gradually conform to in-group norms of co-operative behaviour, learning the benefits of interpersonal reciprocity and trust via direct personal experience (Newton and Norris 2000). However, it also seems obvious that some pre-existent degree of trust is required before a citizen could reasonably join formally constituted civic organisation. To take Putnam's example of American bowling leagues: one would be unlikely to join without some expectation that other members will not cheat, steal the membership fees and so on. It is a more open question as to how generalized trust might relate to informal networks. The same positive reinforcement may occur through repeated exposure. Or it may be that reliance on small friendship groups, for instance in areas where there are few opportunities for formal participation in civil society, may actually bolster distrust in generalized others, while raising the worth of in-group co-operation. Even for formal civic organisations, the experience of membership may not necessarily be positive, for instance local political organisations may encourage cronyism that favours some members over others (Portes 1998).

It seems evident, then, that trusting and joining are likely to be related in some way. However, the nature of the relationship - whether causal or not and under which conditions it may exist - is less clear. Empirical research to date certainly provides substantial evidence in favour of a relationship but it is generally weak on the identification of a causal effect of social connections on the propensity to trust. Numerous studies find membership of civic associations to be correlated with social trust at the individual level (e.g. Almond and Verba 1963; Brehm and Rahn 1997; Hooghe and Derks 1997; Soroka, Johnston and Banting 2005; Stolle and Rochon 1999), although others find no relationship at all, once appropriate controls are introduced (Allum et al. 2010; Claibourn and Martin 2000; Delhey and Newton 2003; Li, Pickles and Savage 2005; Mayer 2003; Uslaner 2002; Whiteley 1999; Wollebaek 
and Selle 2002). Part of the heterogeneity in the evidence on trusting and joining might be due to the way that membership of formal networks has been operationalized. Time spent engaged in these networks may be more important than simply noting the number of different organisations of which citizens are members (Andersen, Curtis and Grabb 2006; Stolle 1998). And some researchers distinguish both between active and passive membership and between 'isolated' and 'connected' organisations, finding relationships between trusting and joining under particular conditions (Mascherini, Vidoni and Manca 2010; Paxton 2007; Sonderkov 2010; Stolle and Rochon 1998; Wollebaek and Selle 2002).

Informal social networks and day-to-day interaction with neighbours, colleagues and acquaintances have also been examined in relation to trust, although less often. (Li, Pickles and Savage 2005; Putnam 1993; Putnam 2000). In a recent paper, Li et al (2008) find some evidence for a correlation between informal friendship network heterogeneity and social capital in the UK. In particular, they find that upwardly socially mobile citizens who gain high status friends tend to be more trusting.

Formal and informal social connections can interact, or assume different relevance for different social groups or cultures. For example, Firdmuc and Gerxhani (2005) show, using Eurobarometer survey data, that while women in some countries are less likely to have formal associational ties, or networks that can provide a job, they are more likely than men to have support networks that can help if they feel depressed or if they need to borrow money. In a similar vein, Pichler and Wallace (2007) show that the pattern of trusting and joining in Europe varies systematically according to region. They find high levels of formal and informal social capital in North-West Europe, high levels of informal social capital in Eastern Europe, and neither kind in Southern Mediterranean Europe. Such evidence is indicative of the empirical associations between trust and informal and formal social connectedness, but casts little or no light on cause and effect, even though the implicit or explicit presupposition of most studies is that interacting with others in either formal or informal settings leads to greater levels of trust and, by implication, social capital (Newton and Norris 2000).

However, as we have suggested at the outset of this paper, a fundamental limitation of this and the other evidence marshalled in support of the effects of social 
connections on interpersonal trust relates to the indeterminacy of the data and statistical models generally employed. The vast majority of extant investigations rely almost entirely on cross-sectional survey data. Because of the well-known inferential limitations of this kind of static, observational data (Halaby 2003; Morgan and Winship) we cannot be confident that the identified relationships, though robust, are not spurious. This concern cannot be dismissed as the pedantry of "the quibbling econometrician" (Glaeser 2001), because any evidence suggesting that factors such as social networks, income, and occupational status cause trust are undermined by the very real possibility that some unmeasured characteristic is the true cause of the observed associations. In short, the majority of the empirical evidence relating formal and informal social connections to the generation of social trust suffers from potentially severe endogeneity bias (Berry 1984; Hausman 1978).

We make no claim for originality in drawing attention to this problem. Indeed, following an initial focus on understanding the ontological status of trust and mapping its longitudinal and comparative trajectory in advanced democracies (Barber 1983; Berg 1996; Coleman 1990; Coleman 1988b; Hall 1999; Paxton 1999; Putnam 2000; Robinson and Jackson 2001; Whiteley 1999), more recent attention has focussed on the question of how social trust is generated, or conversely, how it can be eroded over time (Hooghe and Stolle 2003; Uslaner 2002). These are causal questions and it seems clear that, if we are to develop satisfactory answers, we must move beyond crosssectional analysis, to incorporate research designs that provide greater leverage on the crucial issue of causal identification.

\section{A LONGITUDINAL PERSPECTIVE}

A potentially fruitful strategy for improving understanding of the causes of social trust is to make use of panel (or 'repeated measures') data. The primary advantage of panel data is that, under certain model specifications, it is possible to partial out all observed and unobserved time-invariant characteristics of individual units (Allison 1994; Halaby 2003; Halaby 2004; Wooldridge 2002). As Halaby puts it, "the problem of causal inference is fundamentally one of unobservables, and unobservables are at the heart of the contribution of panel data to solving problems of causal inference" (2003, p2). The incorporation of a longitudinal dimension yields crucial additional leverage on questions of causal order, making it possible to model within-individual change as 
a function of preceding 'events' (Allison 1994). Because this approach is based on the analysis of change in both dependent and independent variables within individuals over time, the estimated model coefficients are purged of the effects of all fixed (or 'time-invariant') respondent characteristics. Such fixed characteristics comprise both the obvious, 'usual suspects' such as gender, age cohort, and ethnicity, as well as less easily measurable variables such as personality traits and pre-adult socialization experiences.

A small number of studies in the existing literature have utilised repeated measures data to examine the causes and consequences of trust (Claibourn and Martin 2000; Li, Pickles and Savage 2005; Stolle and Hooghe 2004a) The primary focus of these studies has been on the relationship between, as Claibourn and Martin pithily put it, "trusting and joining", or the effect of the formal, generalised variant of trust (social trust) on the similar variant of social connection (membership in voluntary organisations). Using the Michigan Socialization Study (Jennings et al. 2004) Claibourn and Martin find weak evidence of an effect of trust on later membership ${ }^{2}$ but no effect of membership on the subsequent propensity to trust. Using the same data, Stolle and Hooghe (2004b) extend Claibourn and Martin's analysis to find that parental trust and membership influence children's subsequent trust and membership, net of children's own previous levels of trust and membership. Li et al (2005) find no effect of membership on later trust, once previous levels of trust are controlled. However, they do find significant direct effects of neighbourhood attachment and social networks on subsequent levels of social trust. Although these investigations make use of repeated measures of social trust, all three are limited to just two waves of data and only Claibourn and Martin (2000) use measures of change on both sides of the equation. This reduces their effectiveness in dealing with omitted variable bias, relative to a specification which includes within-individual variance on both sides of the regression equation (Allison 2005).

\footnotetext{
${ }^{2}$ The evidence is indeed weak as is it is found only in the 'parent' and not the 'child' sample. Even the parental effect is found only in the synchronous, not the lagged effects. The synchronous effects require instrumental variables of unknown status for the purpose of identification.
} 


\section{DATA AND MEASURES}

Data for this analysis come from the British Household Panel Survey (BHPS). The BHPS is a large-scale panel study covering a wide range of topics including household composition, labour market experience, educational attainment, physical and mental health, and social and political attitudes. At wave 1 of the survey, which was conducted in 1991, interviews were completed with a total of approximately 5,500 households and 10,300 individuals. The BHPS has a stratified, multi-stage random sample design, with interviews conducted annually via Computer Assisted Personal Interview (CAPI) with all household members aged 16 and above (see Banks et al (2005) for a detailed account of the BHPS sample design and data collection methodology). Our analyses are based on the 10,264 Original Sample Members (OSMs) who participated in the survey between 1991 and 2008. We exclude temporary or booster sample members and, to retain sample size, allow participants to drop in and out of waves. After taking into account that trust is not measured in every wave (see below) in addition to missing values for membership questions, we are left with approximately 40,000 observations derived from 8,883 individuals. For the fixed effect models these numbers are reduced by approximately half due to individuals maintaining a consistent trust response over the period of analysis.

\section{Variables}

Our dependent variable is the standard generalized trust question, which asks respondents, "In general, would you say that most people can be trusted, or that you can't be too careful these days". The question was administered in the 1998, 2000 and 2003, 2005, 2007 and 2008 waves of the survey. Respondents selecting the 'most people can be trusted' option are coded 1, those selecting 'you can't be too careful' are coded 0 . Respondents who spontaneously reported 'it depends' (2\% over all waves) are also coded 0 , although dropping these cases from the analysis makes no material difference to the results we present here. Table 1 shows descriptive statistics for the trust variable for the period covered by the analysis (1998-2008). Two things are evident. First, although trust is generally considered to be highly stable at the population level over time (Uslaner 2002), the proportion of trusters here exhibits quite substantial variation from year to year, ranging from a high of $44 \%$ in 2003 to a low of $33 \%$ in 2008 . This pattern suggests that generalised trust is quite sensitive to 
macro-level shocks in the external environment, although we have no leverage here on identifying what these events might have been. Second, and related to the first, there is a high level of instability in individual level reports of trust, with nearly half of all sample members changing their trust response at least once over the period of observation. Although a proportion of this individual level change can no doubt be described as random measurement error, we can be confident that there is also a substantial degree of real change in trust over time to be explained in our regressions.

Table 1 Descriptive Statistics for Trust Measure 1998-2008

\begin{tabular}{lcccccc}
\hline Year & 1998 & 2000 & 2003 & 2005 & 2007 & 2008 \\
\hline Trust = No & 4,659 & 4,609 & 3,745 & 4,128 & 3,666 & 3,860 \\
$\%$ & 60.96 & 63.07 & 55.61 & 64.31 & 59.90 & 67.31 \\
Trust = Yes & 2,984 & 2,699 & 2,989 & 2,291 & 2,454 & 1,875 \\
$\%$ & 39.04 & 36.93 & 44.39 & 35.69 & 40.10 & 32.69 \\
Total & 7,643 & 7,308 & 6,734 & 6,419 & 6,120 & 5,735 \\
Change in trust t-1 & & 1,623 & 1,568 & 1,433 & 1,237 & 1,275 \\
$\%$ & & 23.69 & 25.29 & 24.07 & 21.61 & 22.77 \\
Total & & 6,852 & 6,200 & 5,935 & 5,724 & 5,600 \\
No. change 1998-2006 & & & & & & \\
$\%$ & & & & & & 3,016 \\
\hline
\end{tabular}

We use two measures of formal social connections. The first is a count of associational memberships reported by the respondent. The BHPS contains questions about membership of the following organisations and groups: political parties, trade unions, environmental groups, parent associations, tenants/residents groups, religious groups, voluntary service groups, community groups, social/working clubs, sports clubs, and women's groups. Exploratory analysis of the first 10 items (excluding women's groups because very few men report membership) resulted in a twodimensional factor solution, with membership of trade unions, sports groups and social clubs loading on a separate factor. Paxton (2007) argues that membership of these types of groups is indicative of what she terms 'isolated' membership, to the extent that they are weakly correlated with the probability of membership of other groups. Paxton finds isolated membership to be unrelated to trust but connected membership to be strongly related at both the individual and societal level. The 
associational membership variable, therefore, excludes these three indicators from the model, although the results remain essentially unchanged when all organisational types are included. The second measure of formal social connections is a self-report of frequency of attendance at religious services and meetings. Respondents were offered the following response alternatives to denote frequency of attendance: Once a week or more, Less often but at least once a month, Less often but at least once a year, Never or practically, never, Only at weddings, funerals etc.

We also include two measures of informal social connections, both of which measure the frequency of interpersonal contact, rather than the density of networks. The first relates to contact with friends and relatives who are not resident with the respondent: 'How often do you meet friends or relatives who are not living with you?, the second to frequency of talking to neighbours: "How often do you talk to any of your neighbours?' Both questions are answered on a 5 point scale, with the following response options: On most days, once or twice a week, once or twice a month, less often than once a month, never. For the meeting with friends and relatives question, only 24 respondents in the analysis sample used the 'never' category, so this was combined with 'less than one month'. Models are estimated with and without the following vector of covariates: gender, current financial situation, health status over last 12mths, number of children in household, marital status, years of schooling, degree status, unemployment status, income quintiles, age and social class

\section{ANALYSIS}

To assess the relationship between formal and informal of social connections and trust we estimate panel data regressions, with trust predicted by each of the social connection indicators and individual level covariates. The model has the following general form:

$$
\log \left(\frac{P_{i t}}{1-P_{i t}}\right)=\mu_{t}+\beta x_{i t-1}+\gamma_{i}+\alpha_{i}
$$

where $P_{i t}$ is trust measured for individual $i$ at time point $t, \mu_{t}$ is a time-specific intercept and $x_{i t-1}$ is a vector of time-varying independent variables lagged by one 
year. $z_{i}$ is a vector of time-invariant covariates, $\alpha_{i}$ represents the effect of all timeinvariant unmeasured characteristics of sample members, and $\beta$ and $\gamma$ are regression coefficients to be estimated for, respectively, the time-varying and the time-invariant covariate vectors. A parsimonious way of estimating the model in equation (2) is to treat the person specific intercept, $\alpha_{i}$, as a normally distributed random variable with mean zero and variance, $\sigma_{\alpha}^{2}$, the so-called 'random effects' model (Skrondal and Rabe-Hesketh 2004).

A key assumption of the random effects model is that there is zero correlation between $\alpha_{i}$ and the covariate vectors, $\mathrm{E}(\alpha \mid x)=\mathrm{E}(\alpha \mid z)=0$. In substantive terms, this restriction implies that there is zero correlation between the observed covariates and all stable but unobserved influences on trust over the time period. An alternative model specification treats $\alpha_{i}$, not as a random variable, but as a fixed constant for each individual and, thereby, requires no assumptions about the correlation between observed and unobserved causes of the outcome. This is the 'fixed effects' estimator which, though inefficient relative to the random effects model, provides consistent estimates of $\beta$, even when there is a non-zero correlation between the intercept and the independent variables in the model (Allison 2005). The key advantage of the fixed effects estimator, then, is that it yields coefficient estimates that are purged of the effects of all potential time-invariant confounders, both observed and unobserved. It is for this reason that, when the principle threat to valid causal inference relates to omitted variable bias, the fixed effects model is to be preferred (Halaby 2004).

Because our dependent variable here is binary, we use the conditional logit estimator $^{3}$ implemented in Stata 10 (Rabe-Hesketh and Skrondal 2008). To test whether the random or the fixed effects estimates should be preferred we use the Hausman test for omitted variable bias (Hausman 1978). Significant values of the Hausman test indicate that the unit heterogeneity in the random effects model $\left(\alpha_{i}\right)$ has a non-zero correlation with the observed covariates $\left(x_{i t}\right.$ and $\left.z_{i}\right)$ and that the

\footnotetext{
${ }^{3}$ Conditional logistic regression is necessary due to the incidental parameters problem which arises in the case of repeated binary outcomes (see Chamberlain 1980).
} 
parameter estimates for the random effects model are biased by the un-modeled influence of omitted variables (Halaby 2004).

\section{RESULTS}

Table 2 presents the parameter estimates and associated standard errors for the six models, adjusted for the clustered sample design. Models 1 and 4 are equivalent to a standard cross-sectional logit model, with and without controls, respectively. (The controls we employ are: gender, current financial situation, health status over last $12 \mathrm{mths}$, number of children in household, marital status, years of schooling, degree status, unemployment status, income quintiles, age and social class.) The purpose of

Table $2 \quad$ Pooled, Random and Fixed Effect Regression Estimates (logits)

\begin{tabular}{|c|c|c|c|c|c|c|}
\hline & \multicolumn{3}{|c|}{ No controls } & \multicolumn{3}{|c|}{ With Controls } \\
\hline & $\begin{array}{c}\text { Pooled } \\
(1) \\
\end{array}$ & $\begin{array}{c}\mathrm{RE} \\
(2) \\
\end{array}$ & $\begin{array}{l}\mathrm{FE} \\
(3)\end{array}$ & $\begin{array}{c}\text { Pooled } \\
(4) \\
\end{array}$ & $\begin{array}{r}\mathrm{RE} \\
(5) \\
\end{array}$ & $\begin{array}{l}\mathrm{FE} \\
(6)\end{array}$ \\
\hline \multicolumn{7}{|l|}{ Formal connections } \\
\hline Memberships & $\begin{array}{c}0.407 * * * \\
(0.023)\end{array}$ & $\begin{array}{c}0.357 * * * \\
(0.030)\end{array}$ & $\begin{array}{c}0.022 \\
(0.036)\end{array}$ & $\begin{array}{c}0.257 * * * \\
(0.023)\end{array}$ & $\begin{array}{c}0.232 * * * \\
(0.030)\end{array}$ & $\begin{array}{c}0.016 \\
(0.036)\end{array}$ \\
\hline $\begin{array}{l}\text { Religious Attendance } \\
\text { (ref=once a week or more) }\end{array}$ & 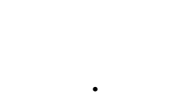 & & - & & & 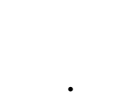 \\
\hline at least once a month & $\begin{array}{l}-0.043 \\
(0.073)\end{array}$ & $\begin{array}{c}-0.226 * \\
(0.102)\end{array}$ & $\begin{array}{l}-0.128 \\
(0.124)\end{array}$ & $\begin{array}{l}-0.114 \\
(0.075)\end{array}$ & $\begin{array}{c}-0.212 * \\
(0.101)\end{array}$ & $\begin{array}{l}-0.125 \\
(0.124)\end{array}$ \\
\hline at least once a year & $\begin{array}{c}0.093 \\
(0.065)\end{array}$ & $\begin{array}{l}-0.184^{*} \\
(0.093)\end{array}$ & $\begin{array}{l}-0.035 \\
(0.124)\end{array}$ & $\begin{array}{c}0.016 \\
(0.066)\end{array}$ & $\begin{array}{l}-0.133 \\
(0.091)\end{array}$ & $\begin{array}{l}-0.035 \\
(0.124)\end{array}$ \\
\hline Never & $\begin{array}{c}-0.188 * * \\
(0.062)\end{array}$ & $\begin{array}{c}-0.467 * * * \\
(0.092)\end{array}$ & $\begin{array}{l}-0.087 \\
(0.128)\end{array}$ & $\begin{array}{l}-0.150^{*} \\
(0.064)\end{array}$ & $\begin{array}{c}-0.335^{* * * *} \\
(0.091)\end{array}$ & $\begin{array}{l}-0.086 \\
(0.128)\end{array}$ \\
\hline $\begin{array}{l}\text { only at weddings, funerals } \\
\text { etc }\end{array}$ & $\begin{array}{c}-0.192 * * \\
(0.060)\end{array}$ & $\begin{array}{c}-0.467 * * * \\
(0.089)\end{array}$ & $\begin{array}{l}-0.114 \\
(0.126)\end{array}$ & $\begin{array}{c}-0.182 * * \\
(0.062)\end{array}$ & $\begin{array}{c}-0.350 * * * \\
(0.088)\end{array}$ & $\begin{array}{l}-0.119 \\
(0.127)\end{array}$ \\
\hline $\begin{array}{l}\text { Informal Connections } \\
\text { Talking to neighbours } \\
\text { (ref=Most days) }\end{array}$ & & & & & & \\
\hline Once or twice a week & $\begin{array}{c}0.090 * * \\
(0.032)\end{array}$ & $\begin{array}{c}0.008 \\
(0.042)\end{array}$ & $\begin{array}{l}-0.073 \\
(0.047)\end{array}$ & $\begin{array}{l}-0.053 \\
(0.032)\end{array}$ & $\begin{array}{l}-0.072 \\
(0.042)\end{array}$ & $\begin{array}{l}-0.078 \\
(0.047)\end{array}$ \\
\hline One or twice a month & $\begin{array}{c}0.044 \\
(0.044)\end{array}$ & $\begin{array}{l}-0.018 \\
(0.059)\end{array}$ & $\begin{array}{l}-0.067 \\
(0.067)\end{array}$ & $\begin{array}{c}-0.143 * * \\
(0.045)\end{array}$ & $\begin{array}{l}-0.120^{*} \\
(0.060)\end{array}$ & $\begin{array}{l}-0.071 \\
(0.067)\end{array}$ \\
\hline Less than once a month & $\begin{array}{l}-0.079 \\
(0.060)\end{array}$ & $\begin{array}{l}-0.082 \\
(0.082)\end{array}$ & $\begin{array}{c}0.005 \\
(0.093)\end{array}$ & $\begin{array}{c}-0.193 * * \\
(0.062)\end{array}$ & $\begin{array}{l}-0.149 \\
(0.083)\end{array}$ & $\begin{array}{l}-0.005 \\
(0.094)\end{array}$ \\
\hline Never & $\begin{array}{l}-0.483 * * * \\
(0.085)\end{array}$ & $\begin{array}{c}-0.433 * * * \\
(0.125)\end{array}$ & $\begin{array}{l}-0.193 \\
(0.140)\end{array}$ & $\begin{array}{c}-0.442 * * * \\
(0.089)\end{array}$ & $\begin{array}{c}-0.381^{* *} \\
(0.125)\end{array}$ & $\begin{array}{l}-0.177 \\
(0.141)\end{array}$ \\
\hline Meeting People & & & & & & \\
\hline
\end{tabular}


(ref=Most days)

Once or twice a week

\begin{tabular}{ccc|ccc}
$0.142 * * *$ & $0.128 * *$ & 0.046 & 0.042 & 0.038 & 0.026
\end{tabular}

$\begin{array}{llllll}(0.028) & (0.039) & (0.042) & (0.029) & (0.039) & (0.043)\end{array}$

One or twice a month

\begin{tabular}{lll|lll}
$0.195 * * *$ & $0.171 * *$ & 0.069 & -0.017 & 0.004 & 0.035
\end{tabular}

$\begin{array}{lllllll}(0.046) & (0.062) & (0.068) & (0.047) & (0.062) & (0.068)\end{array}$

Less than once a

month/never

$\begin{array}{lllllll}0.035 & 0.209 & 0.233 & -0.082 & 0.068 & 0.201\end{array}$

$\begin{array}{lllllll}(0.079) & (0.111) & (0.123) & (0.083) & (0.111) & (0.123)\end{array}$

Constant $-0.617 * * *-0.741 * * *$

(0.063)

$(0.095)$

Random Effect

$1.785 * * *$

$0.683 * * *-1.391 * * *$

$(0.115)$

$(0.169)$

$(0.034)$

Number of observations

38136

38136

38136

8833

\begin{tabular}{llllllll} 
Number of individuals & 8833 & 8833 & 3694 & 8833 & 8833 & 3694 \\
\hline
\end{tabular}

Cluster robust standard errors for pooled logit in parenthesis; * $\mathrm{p}<0.05$

18866

$1.630 * * *$ $(0.035)$

considering these models is to provide a baseline or 'standard' model against which the alternative estimators, which incorporate repeated measures and control for unobserved unit heterogeneity, can be compared. Although there is a one year lag in the measurement of the dependent and independent variables in this model, it is still essentially cross-sectional, because it makes no use of within-individual variance on the either side of the equation. The one year difference between the measurement of the independent and dependent variables may, however, lead to a degree of attenuation in effect sizes relative to contemporaneous measures.

The results of these cross-sectional models support the contention that social connections, of both the formal and informal kind, are causal antecedents of trust. We are more likely to find trusters amongst those with higher levels of associational membership and those who more regularly attend religious ceremonies. Converting the logit coefficients to odds ratios shows that the odds of being a truster increase by $50 \%$ for each additional membership reported, a substantively as well as statistically significant effect. Including controls in model 4 reduces the size of the coefficient for formal memberships by approximately a quarter, although it remains of substantial magnitude (odds ratio $=1.3$ ) and significant at the $99 \%$ level of confidence. Similarly, the probability of trusting is higher amongst those who talk with their neighbours more often, although the pattern of this effect only emerges consistently in model 4, which includes covariates. In model 1 , the coefficients for frequency of meeting with friends and family outside the household are in the opposite direction to theoretical 
expectation, with trust lowest amongst those who report meeting on 'most days', although this effect disappears once controls are introduced in model 4, with none of the coefficients remaining significant at the $95 \%$ level of confidence.

Turning to the random effects estimates, we can see that they are very similar to those obtained using the cross-sectional estimator, although the standard errors are consistently larger, as should be expected. Although the magnitudes of the coefficients are not identical, their pattern of direction and significance tell essentially the same substantive story; social connections have a positive influence on social trust, with formal associational memberships having the strongest effect - a $26 \%$ increase in the odds of trusting for each additional membership reported. However, informal connections also seem to exert a powerful influence, with the odds of trusting being $30 \%$ lower for those reporting they never talk to their neighbours compared to those who report doing this on most days.

A standard reason for reason for preferring the random effect to crosssectional estimators is that it accounts properly for the non-independence of observations made on the same individual over time, yielding correct standard errors and significance tests, where cross-sectional estimators do not (Halaby 2003). However, the parameter estimates of the random effects model are consistent only if the key assumption noted earlier - that the observed predictors of trust in the model are uncorrelated with unobserved time-invariant causes - is empirically justified (Wooldridge 2002). On prima facie grounds, however, it seems unlikely that all unmeasured, time-invariant causes of trust over this time period have zero correlation with the independent variables in table 2 . And, if the true correlation between these unobserved causes and the included covariates is non-zero, the random effects estimator is biased and inconsistent (Rabe-Hesketh and Skrondal 2008). The Chi Square value of the Hausman test in this instance is 135 which, with 25 degrees of freedom, is significant at the $99.9 \%$ level of confidence. Thus, we must reject the random effect assumption and prefer the parameter estimates for the fixed effects models.

The difference between the random and fixed effects estimates in table 2 are substantial. Using the fixed effects estimator, we now find that none of the social connection variables are significant predictors of trust. Note that the fixed effects estimator does not yield estimates for time-invariant variables, which in these models 
are age and gender (coefficients not shown) because these are perfectly collinear with the random intercept, $\alpha_{i}$. While the inability to obtain coefficient estimates for timeinvariant variables may be regarded as an important loss of information, it is in fact the key benefit of the fixed effects framework (Allison 2005; Halaby 2003; Halaby 2004). For, in addition to removing the effects of these observed time-invariant variables, the model also removes the effect of all unobserved variables which result in upwardly biased coefficient estimates in Table 2.

When the effects of unobserved time-invariant confounders are removed, we find both formal and informal social connections to be completely unrelated to trust. Of particular note in this regard is the coefficient for formal associational memberships. While the estimates for this variable are of substantial magnitude and highly significant in both the cross-sectional and random effects models, in the fixed effects models they are close to zero and a long way from reaching statistical significance at conventional levels of confidence. Thus, the effect of associational membership in the cross-sectional estimates derives entirely from between-person variance. If we consider the effect of an individual changing his or her level of associational membership over time, it has no effect at all on the subsequent level of trust. This must lead us to conclude that the strong effect of associational membership in the cross-sectional and random effect models, and presumably those with a similar specification in the existing literature, are subject to substantial endogeneity bias.

It is well known, however, that while the fixed effects estimator is consistent when $\alpha_{i}$ is correlated with the covariate vector, it can also yield considerably less precise estimates of $\beta$ than random effects. This is because fixed effects uses only within-person variability and discards information from units whose score on the dependent variable remains constant over time. Could the difference in the coefficients between the random and fixed effects coefficients simply be due to the difference in statistical power between the two models? Although $52 \%$ of respondents in our analysis sample did not change their trust response over the five waves of observation, this nevertheless yielded a sample of 18863 observations across 3694 individuals, which should yield sufficient power to detect even small associations between the social connectedness variables and trust. It seems safe to conclude, therefore, that the difference in the magnitude and significance of coefficients 
between estimators in table 2 is due to unobserved variable bias in the cross-sectional and random effects models rather than a lack of statistical power in the fixed effects models.

\section{DISCUSSION}

A key tenet of social capital theory is that norms of reciprocity and trust emerge from the formal and informal institutions of civil society (Putnam et al 1993). Citizens become more trusting of one another as they experience the benefits of cooperative behaviour that is fostered within clubs, societies, and associations but also within less formal social networks that exist between friends, relations and neighbours. Enhanced trust, in turn, leads people to become more likely to engage in civic institutions in the future, creating a virtuous circle between social connectedness and trust (Claibourn and Martin, 1997). This process can also unfold in reverse, a phenomenon that prominent academics, politicians, and social commentators have identified as being partly responsible for the increasing atomisation and socio-political disengagement of western citizenries in the latter decades of the twentieth century. These are grand and consequential claims. Yet, the vast majority of the evidence base presented in support of the idea that formal and informal civic engagement fosters trust is based on either descriptive analysis of long-term trends in survey and administrative time-series, or on regression models applied to cross-sectional data (Delhey and Newton 2003; Putnam 2000). It is well-known that such approaches are susceptible to potentially severe biases arising out of the failure to adequately account for unobserved confounding variables (Halaby 2004; Morgan and Winship 2007).

Using conventional cross-sectional regression, our own analysis here lends support to the virtuous circle model; we find trusters to have more 'connected' associational memberships, to more frequently attend religious services, and to talk with their neighbours on a more regular basis. These are not weak effects that rely on small $\mathrm{p}$ values for claims to be taken seriously. Even when a broad range of controls are added to the model, we find that the odds of trusting increase by $25 \%$ for each additional membership an individual reports. However, when we exploit the true value of the repeated measures data available to us - the ability to model withinperson change over time - we find that the cross-sectional estimates are subject to substantial upward bias. Because the fixed effects estimator controls for all observed 
and unobserved fixed characteristics of individual units, the difference in coefficient magnitude between the random and fixed effects coefficients can be interpreted as resulting from the influence of omitted confounding variables (Halaby 2004). Our findings are robust to a number of sensitivity checks relating to the coding and treatment of key variables in our analysis, which have not been reported here due to limitations of space. For instance, our results remain substantively unchanged if we combine the measures of social connectedness in various different ways, including specification as latent variables, in order to mitigate random measurement error in the predictor variables. Similarly, when we operationalize our measure of associational membership as being an 'active' member (rather than just a member), our conclusions are not materially altered.

This type of endogeneity bias can also arise when an outcome variable exerts a causal influence on predictor variables. The models we have used here provide only limited protection against this possibility, through the use of lagged independent variables. And, if the 'virtuous circle' model is to be believed, we should expect the right hand side variables in our equations to themselves be affected by changes in trust at the individual level. However, while the problem of reciprocal causality is certainly an inherent limitation of the approach we have adopted, it is most germane when a fixed effects specification shows a significant, rather than a non-significant effect. This is because the magnitude of any statistically non-zero coefficient will derive, at least in part, from the opposite of the process codified in the statistical model. While it is logically possible that non-significant coefficients can also be biased through reverse causality, via some complex suppression effect, this would appear, on a priori grounds at least, to be rather unlikely in most substantive contexts. In our view, then, our results provide no support for a causal effect in either direction between trusting and joining.

Turning to the substantive implications of our findings, our results lend support to the view that the correlation between associational membership and trust arises from trusters selecting into membership via pre-existing dispositional characteristics (Rothstein and Uslaner 2006; Stolle 1998; Uslaner 2002). This begs the question of what this characteristic, or characteristics, might be. The general unresponsiveness of trust to changes in an individual's formal and informal social connections over a quite substantial period of time certainly accords with the view 
that social trust is not so much a rational reaction to 'the slings and arrows of outrageous fortune' as it is a general outlook which develops early in the life-course and which remains relatively immune to subsequent life-events (Skocpol 2003; Stolle and Hooghe 2004b; Uslaner 2002). This is, of course, a speculation rather than an inference from our empirical analysis. It does, though, suggest a useful focus for future investigations into the origins of social trust. 


\section{REFERENCES}

Allison, Paul. 1994. "Using panel data to estimate the effect of events." Sociological Methods and Research 23:174-199.

—. 2005. Fixed Effects Regression Methods for Longitudinal Data Using SAS. Cary, NC.: SAS Institute Inc.

Allum, N, R Patulny, S. Read, and P Sturgis. 2010. "Re-evaluating the links between social trust, political trust and civic association in Europe." in Spatial and Social Disparities, edited by J Stillwell, P Norman, C Thomas, and P Surridge. London: Springer Verlag.

Almond, G, and S Verba. 1963. The civic culture. Boston: Little,Brown.

Andersen, Robert, James Curtis, and Edward Grabb. 2006. "Trends in Civic Association Activity in Four Democracies: The Special Case of Women in the United States." American Sociological Review 71:376-400.

Arrow, Kenneth J. 1974. The Limits of Organization. New York: Norton.

Barber, Bernard. 1983. The logic and limits of trust. New Brunswick, N.J.: Rutgers University Press.

Berg, A. 1996. "Den nya maten. Gentrixandet - katastrof eller framtidshopp?" in Göteborgs-Posten.

Berry, W D. 1984. Nonrecursive causal models. London: Sage Publications.

Brehm, John, and Wendy Rahn. 1997. "Individual-Level Evidence for the Causes and Consequences of Social Capital." American Journal of Political Science 41: 999-1023.

Claibourn, Michele P., and Paul S. Martin. 2000. "Trusting and Joining? An Empirical Test of the Reciprocal Nature of Social Capital." Political Behaviour 22:267-291.

Coleman, J. S. 1988a. "Social Capital in the Creation of Human-Capital." American Journal of Sociology 94:S95-S120.

Coleman, J.S. 1990. Foundations of Social Theory. Cambridge, MA: Harvard University Press.

Coleman, James. 1988b. "Social Capital in the Creation of Human Capital." American Journal of Sociology 94:95-120.

Crow, G. 2004. "Social Networks and Social Exclusion: An overview of the debate." in Social Networks and Social Exclusion. Sociological and Policy 
Perspectives, edited by Phillipson C, Aallan G, and Morgan D. Aldershot UK and Burlington USA: Ashgate.

de Tocqueville, Alexis. 1835. Democracy in America. New York: Vintage.

Delhey, Jan, and Kenneth Newton. 2003. "Who Trusts? The Origins of Social

Trust in Seven Societies." European Societies 5:93-137.

—. 2005. "Predicting Cross-National Levels of Social Trust: Global Pattern or Nordic Exceptionalism?" European Sociological Review 21:311-327.

Fukayama, Francis. 1995. Trust. New York: Free Press.

Glaeser, Edward L. 2001. "The Formation of Social Capital." ISUMA, Canadian Journal of Foreign Policy 2:34-40.

Granovetter, Mark. 1973. "The Strength of Weak Ties." American Journal of Sociology 78:1360-80.

Halaby, Charles. 2003. "Panel Models for the Analaysis of Change and Growth in Life Course Studies." Pp. 503-527 in Handbook of the Life Course, edited by Jeylan Mortimer and Michael Shanahan. New York: Plenum Press.

-. 2004. "Panel Models in Sociological Research: Theory into Practice." Annual Review of Sociology 30:507-544.

Hall, Peter A. 1999. "Social Capital in Britain." British Journal of Political Science 29:417-461.

Hardin, Russel. 1999. "Do we want to trust in government?" Pp. 22-41 in Democracy and Trust, edited by Mark E Warren. Cambridge: Cambridge Uni Press.

Hausman, J. 1978. "Specification tests in econometrics." Econometrica 46.

Hooghe, M. , and A. Derks. 1997. "Voluntary Associations and the Creation of Social Capital. The Involvement Effect of Participation." Brussel: Centrum voor Sociologie, Vrije Universiteit.

Hooghe, Marc, and Dietland Stolle. 2003. Generating Social Capital: Civil Society and Institutions in Comparative Perspective. New York: Palgrave Macmillan.

Jennings, M. Kent, Gregory B. Markus, Richard G. Niemi, and Laura Stoker. 2004. "Youth-parent socialization panel study, 1965-1997: four waves combined ". Ann Arbor, MI: University of Michigan, Center for Political Studies/Survey Research Center

Keele, Luke. 2005. "Macro Measures and Mechanics of Social Capital." Political Analysis 13:139-156. 
Li, Y., M. Savage, and A. Warde. 2008 "Social Mobility and Social Capital in Britain." British Journal of Sociology 59:497-526.

Li, Yaojun, Andrew Pickles, and Mike Savage. 2005. "Social capital and social trust in Britain." European Sociological Review 21:109-123.

Lin, Nan. 2001. Social capital : a theory of social structure and action. Cambridge, UK ; New York: Cambridge University Press.

Luhmann, N. 1979. Trust and power. Chichester: Wiley.

Mascherini, M., D. Vidoni, and A. Manca. 2010. "Exploring the Determinants of Civil Participation in 14 European Countries: One-Size-Fits None." European Sociological Review.

Mayer, N. 2003. "Democracy in France: Do Associations Matter?" in Generating Social Capital:Civil Society and Institutions in Comparative Perspective, edited by Marc Hooghe and Dietland Stolle. New York: Palgrave Macmillan.

Mill, J. 1937. "An Essay on Government." edited by E. Baker. Cambridge: Cambridge University Press.

Morgan, Stephen, and Christopher Winship. 2007. Counterfactuals and Causal Inference: Methods and Principles for Social Research. New York: Cambridge University Press.

Newton, Kenneth, and Pippa Norris. 2000. "Confidence in public institutions: faith, culture, or performance?" in What's ailing the trilateral democracies?, edited by s. Pharr and Robert Putnam. Princeton: Princeton University Press.

Parsons, Talcott. 1937. Structure of Social Action. New York, NY: The Free Press of Glencoe.

Paxton, Pamela. 1999. "Is Social Capital Declining in the United States? A Multiple Indicator Assessment." The American Journal of Sociology 105:88-127.

—. 2007. "Not All Association Memberships Increase Trust: A Model of Generalized Trust in Thirty-One Countries." Social Forces 86:47-76.

Pichler, Florian, and Claire Wallace. 2007. "Patterns of Formal and Informal Social Capital in Europe." European Sociological Review 23:423-435.

Portes, Alejandro. 1998. "Social Capital: its origins and applications in modern sociology." Annual Review of Sociology 24:1-24.

Putnam, Robert D. 1993. Making Democracy Work: Civic Traditions in Modern Italy. Princeton: Princeton University Press. 
-. 2000. Bowling Alone: The Collapse and Revival of American Community.

New York: Simon and Schuster.

Rabe-Hesketh, Sophia, and Anders Skrondal. 2008. Multilevel and Longitudinal Modeling using Stata (Second Edition). College Station, TX: Stata Press.

Robinson, R. V., and E.F. Jackson. 2001. "Is trust in others declining in America? An age-period-cohort analysis." Social Science Research 30:117-145.

Rothstein, Bo, and Eric M. Uslaner. 2006. "All for All: Equality and Social Trust." World Politics 58.

Simmel, Georg. 1903. "The Metropolis and Mental Life." in The Sociology of Georg Simmel, edited by Wolff Kurt. New York: Free Press.

Skocpol, Theda. 2003. Diminished Democracy. From Membership to Management in American Civic Life. Norman: University of Oklahoma Press

Skrondal, A., \#, and S. Rabe-Hesketh. 2004. Generalized Latent Variable Modeling. Multilevel, Longitudinal and Structural Equation Models. . Boca Raton, FL: Chapman \& Hall.

Sonderkov, K. 2010. "Does generalized social trust lead to associational membership? Unraveling a bowl of well-tossed spaghetti." European Sociological Review.

Soroka, Stuart N., Richard Johnston, and Keith Banting. 2005. "Ethnicity, Ethnic Diversity, Networks, and Trust." Pp. 1-32 in Annual Meeting of the Canadian Political Science Association. London, Ontario.

Stolle, D., and T. Rochon. 1998. "Are All Associations Alike? Member Diversity, Associational Type and the Creation of Social Capital." American Behavioral Scientist 42:47-65.

Stolle, Dietland, and Marc Hooghe. 2004a. "Inaccurate, Exceptional, OneSided or Irrelevant? The Debate about the Alleged Decline of Social Capital and Civic Engagement in Western Societies." British Journal of Political Science 35:149-167.

Stolle, Dietlind. 1998. "Bowling Together, Bowling Alone: The Development of Generalized Trust in Voluntary Associations." Political Psychology 19:497-525. 
—. 2003. "The Sources of Social Capital." Pp. 19-42 in Generating Social Capital: Civil Society and Institutions in Comparative Perspective, edited by Dietland Stolle and Marc Hooghe. New York: Palgrave Macmillan.

Stolle, Dietlind, and T Rochon. 1999. "The Myth of American Exceptionalism: A Three Nation Comparison of Associational Membership and Social Capital." Pp. 192-209 in Social Capital and European Democracy, edited by J. Van Deth, M. Marraffi, K. Newton, and P. Whiteley. London: Routledge.

Stolle, Dietlind, and Marc Hooghe. 2004b. "The Roots of Social Capital: Attitudinal and Network Mechanisms in the Relation between Youth and Adult Indicators of Social Capital." Acta Politica 39:422-441.

Uslaner, Eric M. 2002. The Moral Foundations of Trust. Cambridge: Cambridge University Press.

Whiteley, Paul. 1999. "The Origins of Social Capital." Pp. 25-44 in Social Capital and European Democracy, edited by Jan van Deth, Marco Maraffi, Kenneth Newton, and Paul Whiteley. London: Routledge.

Wollebaek, D., and P. Selle. 2002. "Does participation in voluntary associations contribute to social

capital? The impact of intensity, scope, and type." Nonprofit and Voluntary Sector Quarterly 31:32-61.

Wooldridge, J.M. 2002. Econometric Analysis of Cross-section and Panel Data. Cambridge: M.I.T. Press. 